\title{
Finite element analysis on parameterized model of fiber composite battledore
}

\author{
H Shen* \\ Department of Physical Education, Jinling Institute of \\ Technology, Nanjing, Jiangsu, 211169, China
}

\begin{abstract}
Composite materials have superior properties than single materials, and they have been applied in many fields, for example, sporting goods. In this paper, a battledore was manufactured using fiber composites, and finite element analysis was carried out. The parameterized model of the battledore was established by ANSYS finite element software. Then the displacement, stress and failure of the battledore were analyzed. The results showed that the maximum displacement of the battledore was about 0.9 $\mathrm{mm}$, located at the top of battledore frame, the maximum stress was about $155 \mathrm{MPa}$, located at the junction of battledore frame and rod, and the maximum failure factor was 0.38 , which is higher than that of common aluminum alloy battledore. All the findings suggested that the designed battledore was effective. The battledore has a high safety factor and is worthy of application in practice.
\end{abstract}

\section{INTRODUCTION}

With the development of technology and increase of actual demand, composite materials, as substitutes for many metals, have been more and more widely used in many fields [1], for example, aviation, automobile, navy, because of their advantages of low weight and high strength [2]. Composite materials generally consist of matrix and reinforcement. Different kinds and proportions of reinforcement materials will produce different properties [3, 4]. Many studies have been done on the properties of composites. Greco et al. [5] proposed a new multi-scale model for failure analysis of composite materials. By using the adaptive multilevel domain decomposition method and the fracture criterion that can track the crack path, the numerical calculation was carried out by referring to the complete failure analysis of single-notch fiber reinforced composite beams after three-point bending test. Wu et al. [6] established the drilling model of carbon fiber reinforced composites (CFRP) by finite element software and analyzed the drilling force and torque during drilling process, which made a contribution to reducing the processing defects of CFRP. Christensen [7] tested the failure criteria of fiber reinforced composites, applied sensitivity analysis to the analysis of material failure characteristics, and investigated the future application of the proposed method. Yao et al. [8] analyzed the mechanical properties of laminated carbon fiber composites using MoriTanaka theory and Eshelby equivalent inclusion principle, predicted the elastic properties of the composites by finite element method, and verified the effectiveness of the prediction method through simulation experiments. The wide application of composites promotes the study of their properties, which in turn promotes the development of composites. In recent

*Corresponding Author: huis69@126.com 
years, due to the improvement of people's requirements for sports goods, composite materials have also been widely used in sports goods, for example, fiber composite materials have a good application in the manufacture of sports equipment [9]. In this study, a battledore which was made of fiber composite material was designed. The finite element analysis method was used for constructing the parameterized model of the battledore, and the displacement and stress of the battledore were analyzed to understand the possibility of its application in practice.

\section{FIBROUS COMPOSITE}

Composite material is a new material which combines two or more materials by physical or chemical methods [10]. It can realize the complementary performance of different materials. It can not only maintain and enhance the original properties of materials, but also produce the property that a single material cannot have [11]. Composite materials can improve the mechanical properties of materials by different kinds and proportions of materials, which have been widely used in fields such as aviation, transportation and sports.

Fiber reinforced composites are one of the most widely used composites. It refers to composites which are formed by embedding glass fibers, carbon fibers and other fiber materials into matrix parts by techniques. They are divided into different types according to the different reinforcement parts. They have favorable corrosion resistance and durability, large specific strength and strength and high chemical stability. They have the most widely application in the construction industry because of the excellent performance under severe environment.

Fiber composites have also been well used in sport goods in recent years [12], which can improve the properties of various equipment [13] such as tennis rackets, battledore, race car frames and skis. Battledore which is made of fiber composites is obtained by impregnating fibers in epoxy resin, knitting fibers into cloth and cutting the cloth into pieces proportionally. Battledore which is made of fiber composite material has characteristics of light weight, strong rigidity, small strain, and good damping property, which can prolong the contact time of the ball and increase the acceleration of the ball. In order to further understand the properties of fiber composite battledore, the finite element method was used for analysis.

\section{FINITE ELEMENT ANALYSIS OF FIBER COMPOSITES}

3.1. Finite element analysis

Finite element is a numerical analysis method which is realized through computer [14]. It can divide integrative construction into finite elements for solution. With a high operability, it can simulate multiple physical environment. Moreover, it is featured by short modeling time and high precision. It has been widely applied in machine manufacturing, civil engineering and biomedicine. The procedures of finite element analysis are shown in Figure 1. 


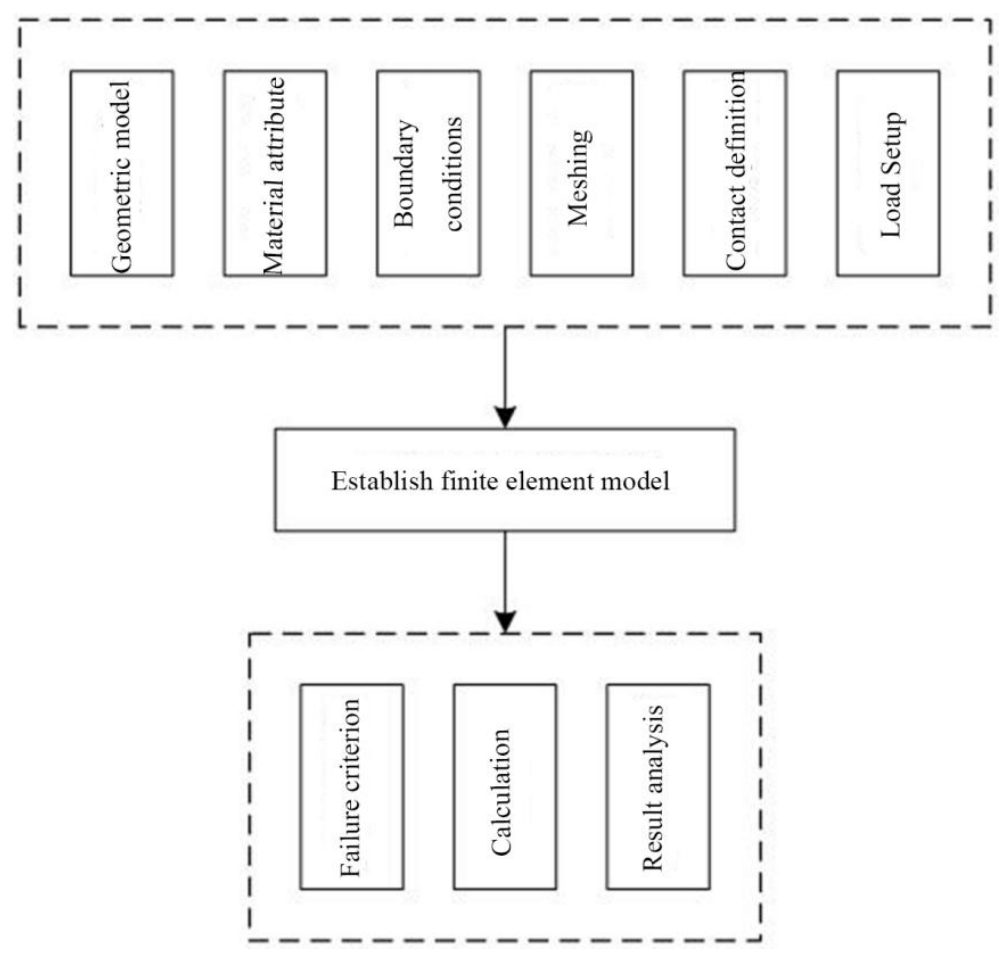

Figure 1: Finite element analysis

\subsection{Geometric model}

Fiber composites are composed of matrix and reinforcement. The cross-section of its geometric model is shown in Figure 2.

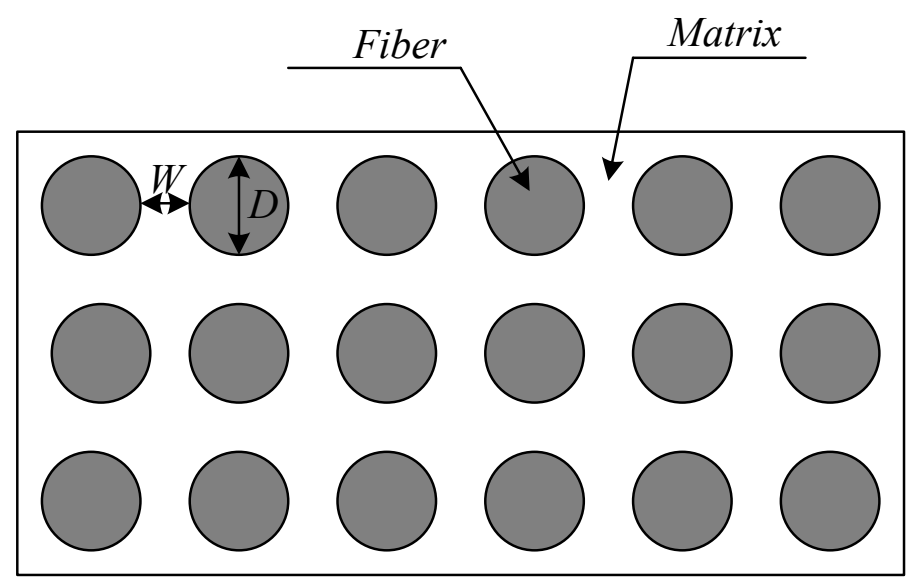

Figure 2: The cross-section of geometric model of fiber composites 
Suppose the diameter of fiber as $D$, the distance between adjacent fibers as $W$, and the volume percent fraction of fiber as $V_{f}$. Their relationship can be expressed as:

$$
W=\left(\sqrt{\frac{\pi}{2 V_{f}}-1}\right) \cdot D .
$$

\subsection{Relevant equations}

The relevant computational formula of the geometric model is as follows.

(1) The following equilibrium equation is obtained according to the stress condition of fiber unit body.

$$
\frac{d \varepsilon_{n}^{f}}{d x}=\frac{1}{D}\left(\alpha_{n-1}^{m}+\alpha_{n}^{m}\right)
$$

where $\varepsilon_{n}^{f}$ stands for the axial stress of cross section of fiber $n, \alpha_{n-1}^{m}$ stands for the shear stress produced by the interaction between the lower part of fiber $n$ and matrix, and $\alpha_{n}^{m}$ stands for the shear stress produced by the interaction between the upper part of fiber $n$ and matrix.

(2) Equation of stress field of composites

Firstly, the shear stress of matrix is calculated according to the axial displacement of two fibers of adjacent matrix:

$$
\alpha_{n}^{m}=G_{m} \frac{u_{n}^{f}-u_{n+1}^{f}}{W}
$$

where $G_{m}$ stands for shear modulus of matrix and $u_{n}^{f}$ stands for the axial displacement of fiber $n$.

Ignoring the change of axial stress of fiber, the normal stress of fiber unit is calculated:

$$
\varepsilon_{n}^{f}=E_{f} \frac{d u_{n}^{f}}{d x}
$$

where $E_{f}$ stands for the Young's modulus of fiber.

Combining equation (3) with equation (4), the following equation is obtained:

$$
\frac{d^{2} u_{n}^{f}}{d x^{2}}-\frac{G_{m}}{E_{f} D W}\left(2 u_{n}^{f}-u_{n+1}^{f}-u_{n-1}^{f}\right)=0 .
$$

Equation (5) is the computational formula of stress field of composites. As it contains many differential equations, equation (5) was processed by dimensionless treatment. 


$$
\kappa=\frac{x}{l_{c}}
$$

where $l_{c}$ stands for length scale, $l_{c}=\sqrt{\frac{W D E_{f}}{G_{m}}}$.

$$
V_{n}^{f}=\frac{u_{n}^{f}}{l_{c}}
$$

After equation (6) and (7) are substituted to equation (5), equation (5) can be simplified as:

$$
\frac{d^{2} V_{n}^{f}}{d \kappa^{2}}-\left(2 V_{n}^{f}-V_{n+1}^{m}-V_{n-1}^{m}\right)=0
$$

then the normal stress is:

$$
\varepsilon_{n}^{f}=E_{f} \frac{d V_{n}^{f}}{d \kappa}
$$

the shear stress is:

$$
\alpha_{n}^{m}=\frac{G_{m}}{W} l_{c}\left(V_{n}^{f}-V_{n+1}^{f}\right)
$$

\section{ESTABLISHMENT OF PARAMETERIZED MODEL OF BATTLEDORE}

\subsection{Size of battledore}

The shaft of the battledore designed in this study has a diameter of $7.2 \mathrm{~mm}$, a thickness of 1.5 $\mathrm{mm}$ and a length of $450 \mathrm{~mm}$. The length of the long axis, length of the short axis and thickness of the battledore frame were $280 \mathrm{~mm}, 220 \mathrm{~mm}$ and $14 \mathrm{~mm}$ respectively. The diameter of the tension wire was $0.7 \mathrm{~mm}$. M40 carbon fiber was used, and the matrix was bisphenol A epoxy resins. The attributes of the composite are shown in Table 1.

Table 1: The attributes of composites

\begin{tabular}{lllll}
\hline $\begin{array}{l}\text { Elasticity modulus } \\
\text { of fiber } \boldsymbol{E}_{\boldsymbol{r}}(\mathbf{G P a})\end{array}$ & $\begin{array}{l}\text { Elasticity modulus } \\
\text { of matrix } \boldsymbol{G}_{\boldsymbol{m}}(\mathbf{G P a})\end{array}$ & $\begin{array}{l}\text { Width of } \\
\text { fiber } \boldsymbol{D}(\boldsymbol{\mu} \mathrm{m}) \text { of fiber } \boldsymbol{\mu}\end{array}$ & \begin{tabular}{l} 
Poisson's ratio \\
\hline 210
\end{tabular} 3.5 & $\begin{array}{l}\text { Poisson's ratio } \\
\text { of matrix } \boldsymbol{\mu}\end{array}$ \\
\hline
\end{tabular}

\subsection{Establishment of model}

The fiber and matrix of the battledore were realized by Solid44 entity unit, and the battledore frame and tension wire are realized by LINK180 unit. In prestressing simulation, pre-tension 
section was established at the contact part of the battledore frame and tension wire through PSMESH command, and pre-tension force was applied by SLOAD to realize parameterization. The braiding form of fiber was two-dimensional and three-directional, the braiding angle was 45 degrees, and the fiber volume ratio was $21.6 \%$. The parametric model of the battledore is as shown in Figure 3.

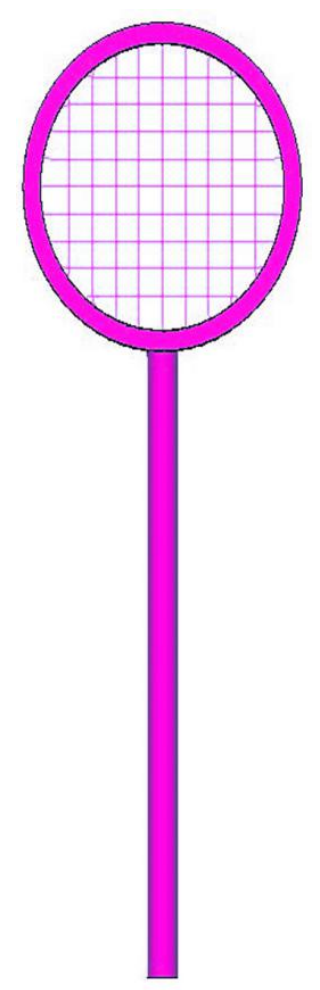

Figure 3: The parameterized model of the battledore

\section{FINITE ELEMENT BASED BATTLEDORE PROPERTY ANALYSIS}

\subsection{Analysis of displacement and stress of battledore}

The stress analysis of the battledore was carried out. According to the actual stress condition, full restraint was given at one end of the battledore parameterized model, and vertical force was applied at the other end. The speed of ball was about $200-300 \mathrm{~km} / \mathrm{h}$, the quality of ball was about 8-10 g, and the diameter of the ball head was about 20-25 mm. In the process of striking, the contact time between the ball and the battledore was about $4 / 1000$ seconds to $6 / 1000$ seconds. A vertical force was exerted in the area which took the midpoint of the tension wire as the center of the circle and $25 \mathrm{~mm}$ as the diameter, and a fixed constraint was exerted at the bottom of the shaft, as shown in Figure 4. 


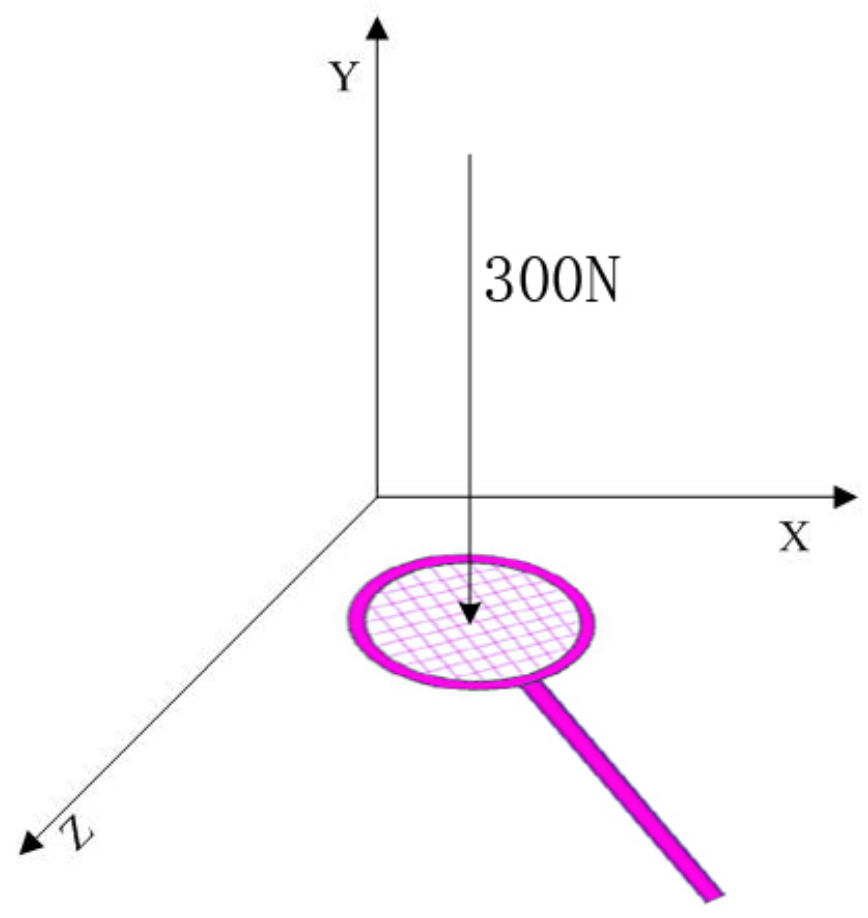

Figure 4: The finite element model during striking

The displacement and stress of the battledore were calculated using finite element software, and the results are shown in Figure 5.

A in Figure 5 is the nephogram of equivalent displacement of the battledore and B is the nephogram of equivalent stress of the battledore. It was found that the maximum equivalent displacement of the battledore was about $0.9 \mathrm{~mm}$, at the top of the battledore frame, the displacement increased from the bottom of the battledore to the top, and the displacement was small overall, indicating that the battledore had a favorable stability when being impacted by the ball. The analysis of equivalent stress of the battledore suggested that the maximum equivalent stress of the battledore was about $155 \mathrm{MPa}$ and the maximum stress concentrated on the junction of the frame and shaft. Stress concentrated at that site because of different shapes of connection between the frame and shaft, indicating that the possibility of fracture was high because of the large stress at the connection between the frame and shaft. Therefore, $\mathrm{T}$ joint can be used at the connection between the frame and shaft in the manufacturing process of battledore to increase stability.

To study the effects of different fiber volume fractions on the battledore, finite element analysis was carried out, and the results are shown in Figure 6.

It was found from Figure 6 that the maximum equivalent stress of the battledore decreased with the increase of fiber volume ratio. But the larger fiber volume meant more fiber material; hence the suitable fiber volume ratio was between $15 \%$ and $20 \%$. 


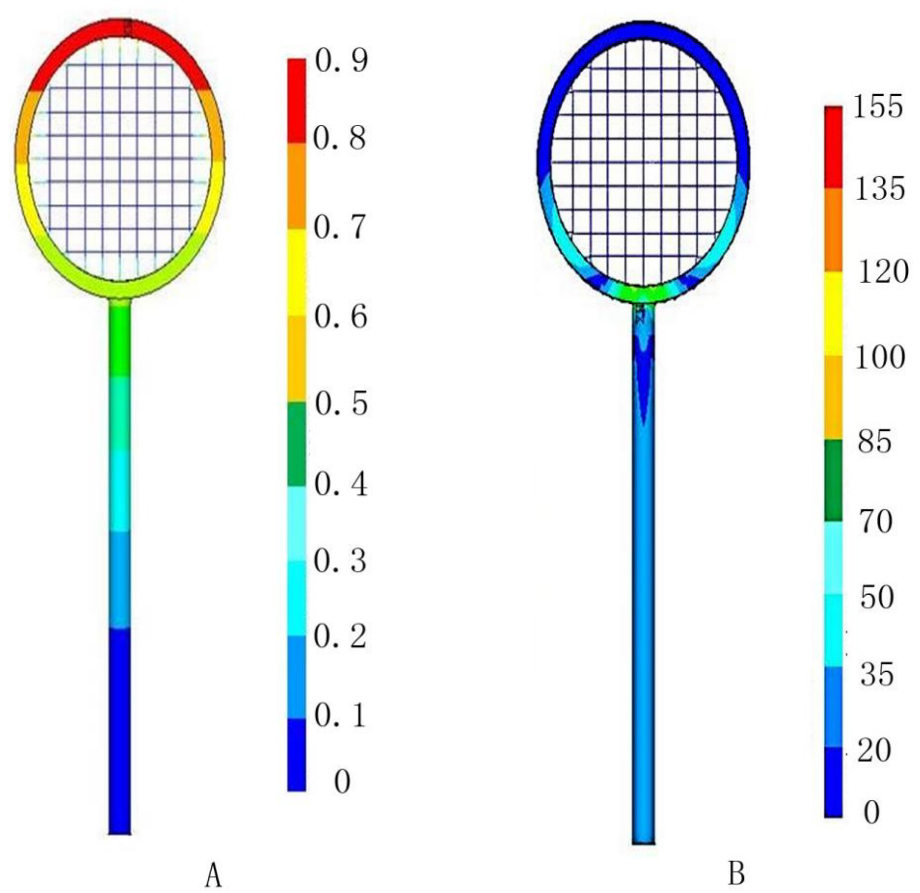

Figure 5: The nephogram of equivalent displacement $(\mathrm{mm})$ and stress $(\mathrm{MPa})$ of the battledore

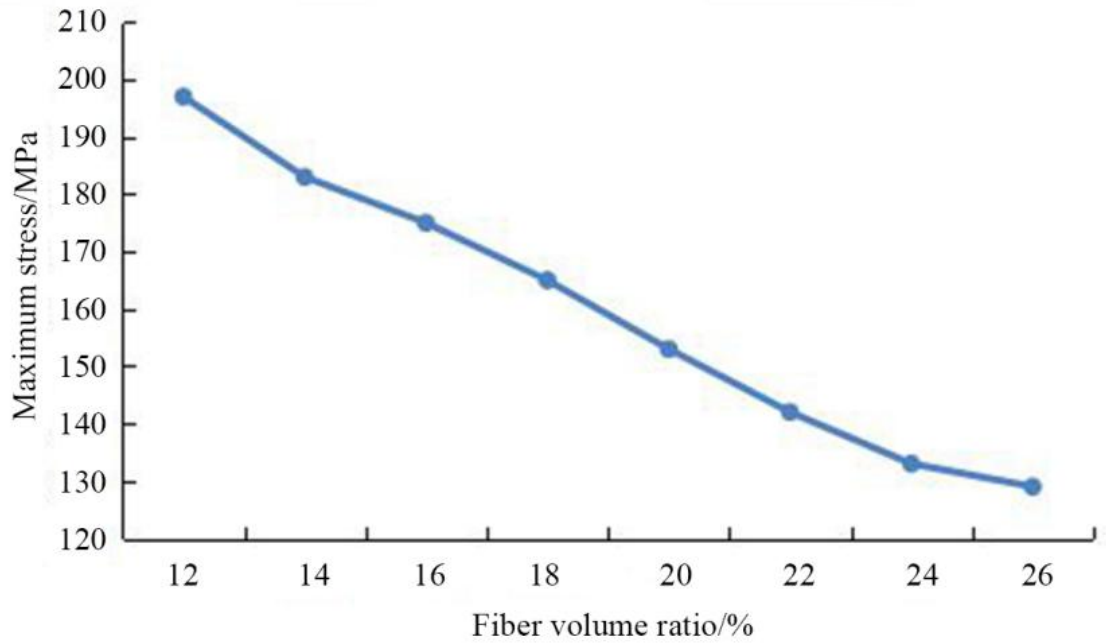

Figure 6: The change of fiber volume ratio and maximum stress 


\subsection{Failure analysis of battledore}

Failure of composite material was discriminated using Tsai-Wu discriminant. Firstly the fundamental strength of the battledore was calculated.

The tensile strength was:

$$
X_{T}=\sigma_{f} V_{f}+\sigma_{m}^{\prime} V_{m}
$$

The compressive strength was:

$$
X_{C}=\sigma_{f}^{-}\left(V_{f}+V_{m} \frac{E_{m}}{E_{f}}\right) .
$$

The shear strength (stretch) was:

$$
Y_{T}=\left[1-\left(\sqrt{V_{f}}-V_{f}\right)\left(1-\frac{E_{m}}{E_{f_{2}}}\right)\right] \sigma_{m} .
$$

The shear strength (compress) was:

$$
Y_{c}=\left[1-\left(\sqrt{V_{f}}-V_{f}\right)\left(1-\frac{E_{m}}{E_{f 2}}\right)\right] \sigma_{m}^{-} .
$$

\begin{tabular}{|c|c|c|c|c|c|c|}
\hline Parameter & $\begin{array}{l}\text { Tensile } \\
\text { fracture } \\
\text { strength of } \\
\text { fiber } \\
\left(\sigma_{f}\right) / \mathrm{GPa}\end{array}$ & $\begin{array}{l}\text { Volume } \\
\text { fraction } \\
\text { of fiber } \\
\left(V_{f}\right)\end{array}$ & $\begin{array}{l}\text { Tensile } \\
\text { stress of } \\
\text { matrix } \\
\text { under fiber } \\
\text { fracture } \\
\text { strain } \\
\left(\sigma_{m}^{\prime}\right) / \mathrm{MPa}\end{array}$ & $\begin{array}{l}\text { Compressiv } \\
\text { strength of } \\
\text { fiber } \\
\left(\sigma_{f}^{-}\right) / \mathrm{GPa}\end{array}$ & $\begin{array}{l}\text { Elastic } \\
\text { modulus of } \\
\text { fiber matrix } \\
\left(E_{m}\right) / \mathrm{GPa}\end{array}$ & $\begin{array}{l}\text { Axial } \\
\text { elastic } \\
\text { modulus of } \\
\text { fiber } \\
\left(E_{f}\right) / G P a\end{array}$ \\
\hline Value & 4.4 & 21.2 & 70.6 & 3.5 & 25.64 & 394 \\
\hline Parameter & $\begin{array}{l}\text { Transverse } \\
\text { modulus of } \\
\text { elasticity } \\
\text { of fiber } \\
\left(E_{f 2}\right) / \mathrm{GPa}\end{array}$ & $\begin{array}{l}\text { Shear } \\
\text { failure } \\
\text { strength } \\
\text { of fiber } \\
\left(\alpha_{f}\right) / \mathrm{MPa}\end{array}$ & $\begin{array}{l}\text { Volume } \\
\text { fraction of } \\
\text { matrix }\left(V_{m}\right)\end{array}$ & $\begin{array}{l}\text { Tensile } \\
\text { failure } \\
\text { strength of } \\
\text { matrix } \\
\left(\sigma_{m}\right) / \mathrm{MPa} \\
\end{array}$ & $\begin{array}{l}\text { Compression } \\
\text { failure } \\
\text { strength }\left(\sigma_{m}^{-}\right)\end{array}$ & $\begin{array}{l}\text { Shear } \\
\text { failure } \\
\text { strength of } \\
\text { matrix } \\
\left(\alpha_{m}\right) / \mathrm{MPa} \\
\end{array}$ \\
\hline Value & 10 & 944 & 56.7 & 80 & 80 & 47 \\
\hline
\end{tabular}

Transverse isotropy surface was:

$$
S_{x y}=\alpha_{f} V_{f}+\alpha_{m} V_{m} .
$$

Table 2: Different parameters of the battledore which is made of composite 
The parameters of failure discrimination obtained through calculation are shown in Table 3.

Table 3: The failure discrimination parameters of the battledore which was made of composite material

\begin{tabular}{llllll}
\hline & $\boldsymbol{X}_{\boldsymbol{T}}$ & $\boldsymbol{X}_{\boldsymbol{C}}$ & $\boldsymbol{Y}_{\boldsymbol{T}}$ & $\boldsymbol{T}_{\boldsymbol{C}}$ & $\boldsymbol{S}_{\boldsymbol{x y}}$ \\
\hline Parameter value & 976.7 & 920.6 & 48.9 & 49.1 & 231.2 \\
\hline
\end{tabular}

Failure analysis of the battledore was carried out by post-processing module in finite element software. The data in Table 3 were input into Tsai-Wu discriminant basis for solution, and then the failure of the battledore was analyzed. According to Tsai-Wu criterion, if the failure factor is greater than or equal to 1 , it can be determined as failure, and if the failure factor is less than 1, it can be determined as valid. The finite element analysis found that the maximum failure factor of the battledore was 0.38 . The same method was used for performing failure discrimination on the ordinary aluminum alloy battledore, and the maximum failure factor was 1.02. It was found from comparison that the failure factor of the battledore designed in this study was smaller than that of the ordinary battledore, which showed that the safety factor of the battledore designed in this study was higher than the ordinary battledore and the design of the battledore was reasonable.

\section{DISCUSSION}

With the progress of technology, there are more and more requirements for the properties of materials. Traditional single materials have not been able to meet the needs of various fields. Composite materials have been paid more and more attention because of their superior properties, and their development speed is very fast. They have important applications in many fields. For example, in the field of aerospace, aircraft components which are made of composite materials have low quality, high strength and good hightemperature resistance [15]. 70\% of some aircrafts are made of composite materials, and also have good applications in satellites, rockets and so on. Composite materials in the field of transportation are mainly used in the design of vehicles. Automobiles which are made of composite materials are lighter in weight and less in fuel consumption [16]. Their excellent elastoplasticity can absorb the impact force produced by impact, thus greatly improving the safety of automobiles. They also have been widely used in ships, railways and other fields. In the field of construction, composite materials as building materials are featured by better heat and sound insulation effect, less water absorption and good corrosion resistance, which can meet the building requirements [17]. Fiber composite materials have excellent applications in building repair and reinforcement and can prolong the service life of buildings at low cost. The wide application of composite materials suggests its importance.

With the improvement of economic level, more and more people participate in sports activities, and people's demand for sports goods also increases. Especially among professional athletes, higher requirements are put forward for the quality of sports goods, and more portable and high-quality materials are applied in the manufacture of sports goods. Composite materials, especially fiber composites, are favored by researchers because of their superior physical and chemical properties and have good applications in the development of various sports equipment, clothing and so on. 
In this study, a battledore was designed based on fiber composite material. In order to analyze the performance of the battledore, the finite element analysis method was used. The finite element method has great advantages in the analysis of composite materials and can accurately and effectively analyze the properties of composite materials. The analysis of the displacement and stress of the battledore suggested that the displacement and stress of the battledore were small, which showed that the battledore had good stability. In addition, the stress concentration at the frame and shaft put forward requirements for the design of battledore, and it can be strengthened by adding components. The failure analysis of the battledore suggested that the maximum failure factor of the battledore was 0.38 , smaller than 1 , while the failure factor of ordinary aluminum alloy badminton racket was 1.02 , smaller than 1. It showed that the safety of the battledore designed in this study was higher than that of the ordinary battledore, which further verified the higher reliability of the battledore.

\section{CONCLUSION}

In this study, the finite element method was used for analyzing the battledore which was made of fiber composite material. The parametric model was established, and the properties were analyzed by ANSYS software. It was found that the displacement and stress of the battledore which was made of fiber composite material were smaller, i.e., it had a good stability. The failure discrimination suggested that the battledore had favorable safety. This study verified the effectiveness of the battledore which was made of composite material and provides some theoretical basis for the actual application of the battledore.

\section{REFERENCES}

[1] Rao, S.S. and Q. Liu, Fuzzy Approach to the Mechanics of Fiber-Reinforced Composite Materials. Aiaa Journal, 2015. 42(42): p. 159-167.

[2] Riley, E.J., E.H. Lenzing, and R.M. Narayanan, Characterization of carbon fiber composite materials for RF applications, Radar Sensor Technology XVIII. International Society for Optics and Photonics, 2014. p. 5450-5453.

[3] Zucchelli, A., M.L. Focarete, C. Gualandi, et al., Electrospun nanofibers for enhancing structural performance of composite materials. Polymers for Advanced Technologies, 2015. 22(3): p. 339-349.

[4] Fernandes, H., H. Zhang, and X. Maldague, An active infrared thermography method for fiber orientation assessment of fiber-reinforced composite materials. Infrared Physics \& Technology, 2015. 72: p. 286-292.

[5] Greco, F., L. Leonetti, and P.N. Blasi, Adaptive multiscale modeling of fiber-reinforced composite materials subjected to transverse microcracking. Composite Structures, 2014. 113(7): p. 249-263.

[6] Wu, M., Y. Gao, Y. Cheng, et al., Carbon Fiber Composite Materials Finite Element Simulation Analysis of Cutting Force. Procedia Cirp, 2016. 56: p. 109-114.

[7] Christensen, R.M., 2013 Timoshenko Medal Award Paper-Completion and Closure on Failure Criteria for Unidirectional Fiber Composite Materials. Journal of Applied Mechanics, 2014, 81(1):011011. 
[8] Yao, Y.Y., X. Wang, and R.S. Dou, Mechanical Properties Prediction of Interlayer Enhanced Laminated Carbon Fiber Composite Materials Containing Inclusions. Key Engineering Materials, 2017. 730: p. 541-547.

[9] Sun, L.N., and Z. Deng, The Carbon Fiber Composite Materials Application in Sports Equipment. Advanced Materials Research, 2012., 341-342: p. 173-176.

[10] Kelly, A., An introduction to composite materials. Concise Encyclopedia of Composite Materials, 2018. 2(1): p. xvii-xxix.

[11] Zhao, D.M., Z.W. Li, L.D. Liu, et al., Progress of Preparation and Application of Graphene/Carbon Nanotube Composite Materials. Acta Chimica Sinica, 2014. 72(2): p. 185.

[12] Tang, D.Z., The Application of Carbon Fiber Materials in Sports Equipment. Applied Mechanics \& Materials, 2014. 443: p.613-616.

[13] Li, L. and H. Jing, Research on the Application of Fiber-Reinforced Composite Materials on Sports Equipments. Applied Mechanics \& Materials, 2014. 687-691: p. 4244-4247.

[14] Britto, J.J.J., A. Vasanthanathan, and P. Nagaraj, Finite Element Modeling and Simulation of Condition Monitoring on Composite Materials Using Piezoelectric Transducers - ANSYS ${ }^{\circledR}$. Materials Today Proceedings, 2018. 5(2): p. 6684-6691.

[15] Sun, C., E.S. Dong, Y.H. Li, et al., Research on EIS-Based Anomaly Detection Technique for Composite Materials. Applied Mechanics \& Materials, 2014, 556562(6):3056-3059.

[16] Samotu, I., M. Dauda, D. Obada, et al., Waste to wealth: A case study of empty water sachet conversion into composite material for automobile application. World Journal of Engineering, 2014. 11(3): p. 199-208.

[17] Gao, Y., W. Yao, J. Sun, et al., A novel soft matter composite material for energy-saving smart windows: from preparation to device application. Journal of Materials Chemistry A, 2015. 3(20): p. 10738-10746. 